\title{
The legitimation crisis of educational change
}

\author{
Dennis Shirley ${ }^{1}$
}

Published online: 16 July 2015

(C) Springer Science+Business Media Dordrecht 2015

When Jürgen Habermas published Legitimation Crisis in 1973, he was responding to the splintering of the social movements of the 1960s with a theory of "universal pragmatics" that would make it possible for citizens with many diverse perspectives to authorize governments to act on behalf of the public good. Without legitimacy there could be no capacity. Furthermore, without legitimacy for governments and their institutions, markets most likely would be turned to as vehicles for public provision.

Later scholars, and in particular Suchman (1995) disaggregated legitimacy into the three components of pragmatic, moral, and cognitive legitimacy. Increasingly, it came to be seen that every set of institutions - corporations, non-profit agencies, and schools for example - would have to persuade the public about its legitimacy across these three domains to survive. Failure to attend to issues around legitimacy could lead to the hollowing out of the state under New Public Management, with diverse provider models increasingly blended with or overtaking traditional civil service agencies. In this neoliberal understanding, markets achieve legitimacy and are the guarantors that government does not plunder public revenues for its own purposes.

The quest for legitimacy has driven many governments to turn to data and a more scientific approach to educational change. On the one hand this is a felicitous development, especially for researchers. On the other hand, the pursuit of certainty through the quantification of education has itself proved nettlesome. It seems that the mathematization of teaching and learning can conceal a number of blind spots that can create new problems for teachers and students. How this occurs and can be

Dennis Shirley

dennis.shirley@bc.edu

1 Lynch School of Education, Boston College, 140 Commonwealth Avenue, Campion Hall, Chestnut Hill, MA 02467-3813, USA 
overcome is represented vividly in this new issue of The Journal of Educational Change.

The first article, entitled "Mathematics, PISA, and culture: An unpredictable relationship," by Paul Andrews, inquires into the outstanding mathematics performance of students in Flanders, a Dutch-speaking jurisdiction in Belgium. Andrews argues that Flanders' achievement has been overlooked because its results usually are aggregated together with those of all of Belgium. Why has Flanders done so well? Andrews postulates that Flanders reveals a particularly generative mathematics teaching script, which he and his colleague Judy Sayers previously defined as "the culturally determined patterns of belief and behavior, frequently beneath articulation, that distinguish one set of teachers from their culturally different colleagues." (2013, p. 133)

How do we know that Flanders has such a script? Andrews contends that a confluence of two didactic traditions in mathematics education is visible in Flanders. The first of these refers to Nicholas Bourbaki and his followers, who propounded an abstract, structuralist approach to mathematics. The second refers to "realistic mathematics education," which emphasizes the study of real problems that students solve through their own subjective reinvention. The article then turns to analyses of actual mathematics instruction in Flanders and how these two traditions interact in the pedagogies of teachers who are judged to be highly skilled by their colleagues.

Andrews' article is provocative because it invites a cultural turn away from the rather one-sided literature on educational policy to an analysis of PISA data that focuses on pedagogy. Flanders exists in the context of a diverse multicultural democracy, unlike jurisdictions such as Shanghai, Japan, and South Korea that are often pointed to as exemplars of high achievement. Teaching scripts that animate everyday classroom pedagogies and are documented by Andrews provide rewarding insights in this account.

A cultural turn necessitates greater attentiveness not just to how individuals behave, but also how they think. The second article in this issue, entitled "Studentinvolved data use: Establishing the evidence base" by Jo Beth Jimerson and Ellen Reames probes the current popularity of student "data walls," "data binders," and "data folders." As part of a drive to uplift student achievement, schools throughout the United States and many other nations recently have been providing students with access to all of their testing data in an effort to make their learning more transparent and actionable. Unfortunately, this well-intentioned effort has ignored the wellestablished research on achievement goal theory (Blackwell et al. 2007; Dweck 2006; Meese et al. 2006) that indicates that many students, and perhaps most educators, ascribe to performance orientations that naturalize student achievement as something fixed and relatively unalterable by interventions.

The research persuasively demonstrates that a growth orientation is far more productive of learning - as well as implicitly dignifying of students' thirst for understanding. Still, the pervasiveness of performance orientations among educators and society at large does not change easily. Immersing students in reams of data that exposes those with poor performance, if not undertaken with considerable tact and encouragement, could confirm and reinforce their already negative self-conceptions. 
Providing educators with an abundance of data showing that privileged students prevail and impoverished students struggle could backfire by providing teachers with evidence to support pre-existing racial, gender, ethnic, and social class biases. Data in these cases would be far from neutral; it would rather provide an only apparently scientific reference that would consolidate the social reproductive dimensions of schooling.

It is important to note that at no point in this article do Jimerson and Reames argue against student-involved data use. They do, however, raise a warning that this is a widely disseminated practice without an evidentiary base. Consequently, they ask educators and policy makers to be alert to potentially negative aspects of this practice, especially when it could discriminate against struggling students. Here is a clear call to readers of the Journal of Educational Change who are working in schools to exercise moral leadership and to inquire more closely into why certain practices are spreading and to ask after evidence that it is improving student learning. Otherwise, student-involved data use may have practical legitimacy because it is in accord with government policies and cognitive legitimacy because it makes implicit sense, but may lack moral legitimacy because there is so little evidence that it improves learning.

It isn't only students whose learning increasingly is becoming quantified in an age of big data. It is also the assessment of classroom teachers, as Mary Lynne Derrington and John Campbell show in "Implementing new teacher evaluation systems: Principals' concerns and supervisor support." Their study focused on a southeastern state in the US that was one of the first to receive federal Race to the Top funding, which among its many criteria required that teacher effect ratings be provided by school principals based on the principals' in-class evaluations of their staff. Derrington and Campbell wanted to understand how principals viewed the new teacher evaluation systems and how they accommodated them with reference to the well-known "stages of concern" model developed by Hall and Hord (2015). Did principals and their supervisors welcome the additional power they would wield to judge the quality of their teachers?

Race to the Top in the US has not removed any of the previous responsibilities from principals, so it is not surprising that it initially met with great resistance by principals in this southeastern state. They especially were pained to discover that the greater focus on formal evaluations necessarily meant less time for everyday prosaic interactions with students and teachers. Principals' visibility in the hallways declined. They found themselves spending more and more time on formal evaluations. The job was less satisfying.

Educators, however, are adaptive. As time passed principals learned to accommodate the new demands as they worked with their supervisors to redistribute roles in ways that complied with Race to the Top. Their staff learned that there were advantages to more formal evaluations as not so much weight was placed on a single assessment. While the overall tone of the article by Derrington and Campbell is critical of government policy, the reader is persuaded that school leaders in the southeastern state have risen to the challenge posed by Race to the Top and done so admirably. 
Intriguingly, the US state under review by Derrington and Campbell posted first in the country in gains on the National Assessment of Educational Progress in 2013 (US Department of Education). It is not clear whether the new teacher evaluation systems deserve credit for this, because other reforms, such as implementation of the Common Core State Standards, were underway during the same time period. The Common Core is credited (Carmichael et al. 2010) with raising academic standards beyond those previously in place in many states and in particular in those with lower achievement results. For advocates of educational policies favored by the Obama administration, the gains were considered to be evidence in favor of its programs.

If the Race to the Top data provide evidence that the push for accountability won an important victory in an early adopter state in the US, the next article in this series, by James Nehring and Stacy Szczesiul, raises persistent questions about the hidden costs of accountability systems. The authors studied an "Integrated" (mixed-faith) secondary school in Northern Ireland as part of a broader international study entitled Redefining High Performance. Their study revealed that even when a school achieves well above its peers on standardized examinations, it can do so by neglecting more complex measures of twenty-first century skills that call on students to excel not only with traditional academics but also with interpersonal skills and higher order critical thinking.

Intriguingly, the Irish school studied by Nehring and Szczesiul does have internal resources that can help its educators to teach twenty-first century skills. The teachers have high levels of pedagogical content knowledge and are highly respected. The school has pastoral care programs with social dimensions to ensure that students develop well in regard to their ability to get along with others. Given Northern Ireland's troubled history of inter-religious conflict, the government has responded by creating carefully designed cross-community projects that enable students to learn together as part of a tolerant and engaged community.

Unfortunately, the authors find that the push for accountability in Northern Ireland does not enable these strengths within the system to find their full expression. Data in this case do not lead to education but rather to its deformation as a drive to master easily tested content is prioritized. Northern Ireland, the study reveals, will not attain twenty-first century skills until its stress on accountability is balanced with other considerations that will require time and space to mature.

The fifth article in this issue, entitled "Improving anti-bullying initiatives: The role of an expanded research agenda" by Sigrun Ertesvåg, returns to the question of the role of data in schools. Ertesvåg reviews the high status of randomized control trials and quasi-experimental designs in anti-bullying research, which have shown that the best programs do not focus on single classrooms but instead involve the whole school. Unfortunately, the very schools that are most needful of anti-bullying programs are those with little capacity to improve because their teachers are not given opportunities to collaborate, innovate, or to lead. To ask demoralized and isolated teachers to create programs focused on bullying or student well being in general is to ignore the limited power of data alone to catalyze change. One must instead take school cultures seriously and begin by recovering a sense of trust, optimism, and capacity among the staff. 
Taken together, these five articles point us in promising directions for improving our schools and enhancing the legitimacy of our public educational systems. Paul Andrews' manuscript on teaching scripts in Flanders invites us to examine our own often unconscious scripts and teachers' inventive blends of different didactic traditions. Jo Beth Jimerson and Ellen Reames' study of student-involved data-use encourages us to step back from data as a panacea and instead to inquire into the diverse cultural and professional mindsets with which our educators and our students are engaging with data. Mary Lynne Derrington and John Campbell, while critical of Race to the Top, show that educational leaders have evolved and adapted in ways that accommodated teacher evaluation well into their overall repertoire of practices. All three of these pieces involve insightful criticisms of some governmental policies as well as leading policy analysts who overlook the cultural and social psychological dimensions of education.

James Nehring and Stacy Szczesiul, the fourth article, show that even if accountability systems do promote some transparency about student achievement they should not be over-emphasized as they can undermine the most important twenty-first century skills. Importantly, they demonstrate that schools currently possess important resources that can be leveraged to facilitate the transition to deeper levels of teamwork, independent reflection, and innovation. Finally, Sigrun Ertesvåg indicates that anti-bullying programs must engage more intentionally with the dynamics of school cultures and especially the capacity and freedom of the educators working in them to scaffold their leadership over time so that they can better promote the safety and ultimately the flourishing of their students.

This is a critical time in the history of public education. The legitimacy of what the Scandinavians (Blossing et al. 2014) call "a school for all" is increasingly and insistently questioned as cyberschools, home schooling, and for-profit education proliferates around the world. On the one hand, these can entail positive developments when they supplement rather than replace public schools. Yet as Ertesvåg explains, the concept of a "school for all" in the Nordic nations, strategically adapted from the democratic humanism of John Dewey, retains a powerful pragmatic, moral, and cognitive legitimacy because of its tenaciously inclusive and normative commitments. Significantly, we are now approaching the centennial observation of Dewey's masterful Democracy and Education (1916). These five articles, even when sharply critical of some dimensions of contemporary public schooling, ultimately provide us with invaluable resources for overcoming education's legitimation crisis and securing the sustainability of a "school for all" in the twenty-first century and beyond.

\section{References}

Andrews, P., \& Sayers, J. (2013). Comparative studies of mathematics teaching: Does the means of analysis determine the outcome? ZDM: The International Journal on Mathematics Education, 45(1), $133-144$. 
Blackwell, L. D., Trzesniewski, K. H., \& Dweck, C. S. (2007). Implicit theories of intelligence predict achievement across an adolescent transition: A longitudinal study and an intervention. Child Development, 78(1), 246-263.

Blossing, U., Imsen, G., \& Moos, L. (2014). The Nordic education model_ “A school for all” encounters neo-liberal policy. New York: Springer.

Carmichael, S. B., Martino, G., Porter-Magee, K., \& Wilson, W. S. (2010). The state of state standardsand the common core-in 2010. New York: Fordham Institute.

Dewey, J. (1916). Democracy and education: An introduction to the philosophy of education. New York: MacMillan.

Dweck, C. S. (2006). Mindset: The new psychology of success. New York: Ballantine.

Habermas, J. (1973). Legitimation Crisis. Boston: Beacon Press.

Hall, G. E., \& Hord, S. M. (2015). Implementing change: Patterns, principals, and potholes. Boston, MA: Pearson Education.

Meese, J. L., Anderman, E. M., \& Anderman, L. H. (2006). Classroom goal structure, student motivation, and academic achievement. Annual Review of Psychology, 57, 487-503.

Suchman, M. (1995). Managing legitimacy: Strategic and institutional approaches. Academy of Management Review, 20(3), 571-610.

United States Department of Education. (2013). A first look: 2013 mathematics and reading. Washington, DC: National Center for Education Statistics. 